\title{
Management of Atherosclerosis: Prospect of Functional Foods and Nutraceuticals
}

\author{
A.M. Adewolu*, F.G. Olorunfemi \\ Department of Biochemistry, College of Medicine, University of Lagos, Nigeria \\ *Corresponding Author: A.M. Adewolu, Department of Biochemistry, College of Medicine, University \\ of Lagos, Nigeria.

\begin{abstract}
Functional foods and nutraceuticals are potentially healthy foods that play major roles in maintaining a healthy state of well-being by protecting and preventing against various diseases. No doubt about it, Atherosclerosis remains one of the leading causes of death in developed and underprivileged countries as a result of high intake of western-styled diets. Despite advancement in clinical treatments, cases of atherosclerosis still remain high worldwide. We briefly review the prospect of bioactive compounds naturally found in foods and as functional ingredients not limited to omega-3 fatty acids, fibers, polyphenols, carotenoids, quercetin etc needed for the prevention and treatment of Atherosclerotic vascular disease.
\end{abstract}

\section{INTRODUCTION}

Cardiovascular diseases (CVD), of which atherosclerotic vascular disease is by far the largest component, remain the leading cause of morbidity and mortality worldwide (Massaro et al., 2010). Although genetic factors and aging are important in determining the overall risk, a substantial proportion of CVD occur in conjunction with a series of modifiable risk factors, such as hypercholesterolemia, hypertension, obesity, insulin resistance, and diabetes, susceptible to lifestyle modifications, which include diet and physical exercise (Galimanis et al., 2009). Risk factors are manifold, but inflammation and elevated low-density lipoprotein (LDL) cholesterol are thought to be among the most important contributors (Alenghat and Davis, 2019). Failure to prevent and treat hypercholesterolemia is the main threat for cardiovascular illness, adversely affecting the myocardium itself and promoting atherosclerosis (Csonka et al., 2016). Although, the marketplace offers numerous kinds of medications of CVD that may be given alone or with other treatments, these medications have disagreeable side effects, we need an extensive investigation into natural treatments of functional food or medicinal plant as complementary or alternative therapies (Laudadio et al., 2015; Tufarelli et al., 2016).

Nutritional interventions are effective and - in theory - easy to implement primary and secondary prevention strategies that reduce several risk factors of atherosclerosis and CVD (Visioli and Poli 2019; Visioli et al. 2008). The interest in phytochemicals found in plant foods as bioactive components of the diet have gotten much attention in recent years. Various epidemiological and clinical studies have shown that the risk of CVD is reduced by diet rich in vegetables, fruits, unrefined grains, fish and low-fat dairy products, and foods like brans, nuts, which are low in saturated fats and sodium are helpful. Furthermore, foods containing mono- and polyunsaturated fats, plant sterols and soy proteins have all been documented to have a helpful effect on lipid profile and the overall CV health. Functional foods and nutraceuticals, thus, play vital roles in the functioning of various body organs, important in maintaining health and reducing the risk of various diseases. On this background, this review will focus on the mechanism and prospect of functional foods and nutraceuticals that are labeled as cardioprotective towards managing Atherosclerotic cardiovascular disease. 


\section{The Pathogenesis of Atherosclerotic Vascular Disease}

A description of the cellular and molecular events underlying atherosclerosis is important for understanding the mode of action of cardioprotective functional foods and nutraceuticals. A brief review of current concepts of inflammation and atherosclerosis gives the proper background to place their effects in context. In its initial stages, atherosclerosis is characterized by the intimal recruitment of selected populations of white blood cells, especially monocytes, and by the gradual accumulation of lipids and extracellular matrix. The endothelium and the underlying collagen layers overlying the enlarged intima - the so-called fibrous cap-for a long time during atherosclerosis progression prevent the contact of the highly thrombogenic lipid core of the plaque with the circulating blood. The sudden rupture of the eventually thin fibrous cap, from the outside or from the inside (in the latter case due to the rupture of vasa vasorum penetrating the intima), transforms this slow process into an acute event, with the sudden development of thrombosis (Ross, 1999). When this occurs in a coronary artery, the consequent myocardial ischemia, in appropriate conditions, may precipitate an acute coronary syndrome, that is, acute myocardial infarction or unstable angina. In the cerebral circulation or in the cerebro-afferent arteries this may lead to an acute stroke.

The recruitment of monocytes reflects specific molecular changes in the adhesive properties of the endothelial surface, due to the surface expression of specific endothelium-leukocyte adhesion molecules (ELAMs) ("athero-ELAMs"). One of the most relevant such proteins is vascular cell adhesion molecule-1 (VCAM-1). Pathophysiologically, relevant stimuli for VCAM-1 expression include several causes of increased oxidative stress, such as oxidized low density lipoproteins (LDL), many cytokines, the advanced glycation end-products (AGEs) associated with diabetes, and possibly also high glucose and high insulin (Madonna and De Caterina, 2009). Once adhered, monocytes transmigrate, through the action of chemotactic stimuli also deriving from the activated endothelium, from the blood into the subendothelial intima, where, upon internalization of modified lipoproteins, they become macrophages able to secrete proinflammatory cytokines. These contribute to maintaining a state of vascular inflammation, further augmenting the expression of adhesion molecules, chemoattractants, and macrophage-activating factors, thus initiating a vicious circle leading to lesion progression.

Later on, the production of matrix metalloproteinases (MMPs) - by the same macrophages as well as by endothelial cells - may promote the erosion of the collagen layers of the fibrous cap and ultimately lead to plaque rupture (Libby, 2003). The stability of the atherosclerotic plaque is indeed thought to reflect the balance and interplay of various dynamic factors, including endothelial dysfunction, the proliferation of smooth muscle cells (which are mainly responsible for the synthesis of collagen), and the degradation of collagen and other elements of the extracellular matrix by MMPs, mostly produced by activated macrophages. The much sought-after prevention of acute vascular events therefore requires interventions that affect such mechanisms leading on the one hand to the slow formation of atherosclerotic lesions and on the other to the sudden precipitation of plaque rupture.

\section{FUnCTIONAL FOODS AND NUTRACEUTICALS}

The notion that foods not only provide basic nutrition but can also prevent diseases and ensure good health and longevity is now attained greater prominence (Ferrari, 2004). Various terms have been used interchangeably to designate foods for disease prevention and health promotion. The term Nutraceuticals was introduced in 1989 by the US Foundation for Innovation in Medicine and referred to "any substance that is a food or a part of a food and provides medical or health benefits, including the prevention and treatment of disease" (De Felice, 1994). In 1994, the US Institute of Medicine's Food and Nutrition Board defined functional foods as "any food or food ingredient that may provide a health benefit beyond the traditional nutrients it contains" (Bjelakovic and Gluud, 2007).

Functional foods, containing physiologically active components either from plant or animal sources, marketed with the claim of their ability to reduce heart disease risk focusing primarily on established risk factors, that is, blood cholesterol, diabetes, and hypertension. Functional foods are suspected to exert their cardioprotective effects mainly through lipid lowering effects, antioxidant actions, and/or decreased homocysteine levels. The table below shows some cardio-protective functional foods and nutraceuticals with their bioactive compounds; 
Table1. Cardio-protective functional foods and nutraceuticals with their respective bioactive compounds and mechanism of action

\begin{tabular}{|c|c|c|c|}
\hline Functional foods & Bioactive compounds & Potential mechanism & References \\
\hline -Nuts & $\begin{array}{l}\text {-Tocopherols, omega-3fatty } \\
\text { acids }\end{array}$ & & Sabate and Ang, 2009 \\
\hline -Legumes & -Fiber and polyphenols & & Erkkila and Lichtenstein, 2006 \\
\hline -Fruits and vegetables & -Fiber (pectin) & $\begin{array}{l}\text { Lowering blood } \\
\text { cholesterol }\end{array}$ & Liu et al., 2002 \\
\hline -Dark chocolate & -Flavonoid & & Grassi et al., 2005 \\
\hline -Soy proteins & -Genistein and daidzein & & $\begin{array}{l}\text { Lutsey et al., } 2007 \\
\text { Anderson et al., } 1995\end{array}$ \\
\hline $\begin{array}{l}\text {-Green leafy } \\
\text { vegetables, fruits }\end{array}$ & -Carotenoids & & Chopra et al., 2000 \\
\hline -Citrus fruits & -Vitamin C & $\begin{array}{l}\text { Inhibition of LDL-C } \\
\text { oxidation }\end{array}$ & Sesso et al., 2008 \\
\hline -Tomato & -Lycopene & & Aguirre and May, 2008 \\
\hline -Pomegranate & -Polyphenols & & Davidson et al., 2009 \\
\hline -Fish & -Omega-3 fatty acids & & Lee and Wander, 2005 \\
\hline -Onion and garlic & -Quercetin & & Hooper et al., 2008 \\
\hline $\begin{array}{l}\text {-Green \& black teas } \\
\text {-Ginseng }\end{array}$ & $\begin{array}{l}\text {-Tea polyphenols } \\
\text {-Ginsenosides }\end{array}$ & $\begin{array}{l}\text { Decreasing blood } \\
\text { pressure }\end{array}$ & \\
\hline -Fruits and vegetables & -Folate and phytochemicals & Lowering blood & Samman et al., 2003 \\
\hline -Whole grains & -Fiber and phytochemicals & homocysteine & Appel et al., 2000 \\
\hline -Nuts, seeds, and oils & -Vitamin E & & Broekmans et al., 2000 \\
\hline -Tomatoes & -Lycopene & & Engelhard et al., 2006 \\
\hline $\begin{array}{l}\text {-Green leafy } \\
\text { vegetables, fruits }\end{array}$ & -Carotenoids & Antioxidant action & Krinsky and Johnson, 2005 \\
\hline -Vegetable oils & -Tocopherol, tocotrienols & & Sesso et al., 2008 \\
\hline -Grapes and red wines & $\begin{array}{l}\text {-Anthocyanins, catechins, } \\
\text { flavonols, myricetin }\end{array}$ & & $\begin{array}{l}\text { Perez-Jimenez and Saura-Calixto, } \\
2008\end{array}$ \\
\hline -Nuts, seeds, and oil & -Vitamin E & & Singh et al., 2005 \\
\hline -Fish & -Omega-3 fatty acids & & Kushi et al., 1996 \\
\hline -Legumes & -Polyphenols & $\begin{array}{l}\text { Anti-inflammatory } \\
\text { action }\end{array}$ & Lutsey et al., 2007 \\
\hline -Grapes and red wines & $\begin{array}{l}\text {-Anthocyanins, catechins, } \\
\text { flavonols, myricetin }\end{array}$ & & $\begin{array}{l}\text { Perez-Jimenez and Saura-Calixto, } \\
2008\end{array}$ \\
\hline -Fish & -Omega-3 fatty acids & & Ueedal et al., 2008 \\
\hline -Nuts & -Polyphenols & & Ros et al., 2004 \\
\hline -Citrus fruits & -Vitamin C & Endothelial function & Aguirre and May, 2008 \\
\hline -Grapes and red wines & $\begin{array}{l}\text {-Anthocyanins, catechins, } \\
\text { flavonols, myricetin }\end{array}$ & & $\begin{array}{l}\text { Perez-Jimenez and Saura-Calixto, } \\
2008\end{array}$ \\
\hline -Dark chocolate & -Flavonoid & & Grassi et al., 2005 \\
\hline
\end{tabular}


Potential mechanisms for the cardio-protective effects of $n-3$ fatty acids are suggested to be; antiinflammatory, antithrombotic (reduced platelet aggregability), and antiarrhythmic (reducing the risk of potentially fatal cardiac arrhythmias), lowering of heart rate and blood

pressure, hypotriglyceridemic, and improved endothelial function (Mozaffarian, 2008). N-3 fatty acids suppress the production of interleukin-2, the acute phase reactants and modify the production of eicosanoids, such as thromboxane A2, leukotriene B4, leading to reduced inflammation. The mechanisms by which fruit and vegetables exert their protective effects are not entirely clear but likely include antioxidant and anti-inflammatory effects. Among the possible explanations for this beneficial effect, fruits and vegetables have been found to decrease susceptibility of LDL particles to oxidation (Chopra et al., 2000). Several bioactive components in fruits and vegetables such as carotenoids, vitamin $\mathrm{C}$, fiber, magnesium, and potassium act synergistically or antagonistically to promote a holistic beneficial effect. The totality of the evidence supports current dietary guidelines to increase fruit and vegetable consumption to at least five. Soluble fibres including pectins from apples and citrus fruits, $\beta$-glucan from oats and barley, and fibres from flaxseed and psyllium are known to lower LDL-C (Erkkil"a and Lichtenstein, 2006). The mechanisms of their cholesterol-lowering effects are suggested to be the binding of bile acids and inhibition of cholesterol synthesis.

\section{CONClusion}

The management, prevention and treatment of atherosclerotic vascular disease are based on lifestyle, hereditary factors and physical activity. Nutrition represents a possible strategy for management and prevention of this disease.

It is now evident, based on the extensive scientific evidence, that functional foods and nutraceuticals have broad ranging physiologic effects in vivo that lessen inflammatory cascades and vascular reactivity. These effects are as powerful as pharmaceutical interventions, yet much safer. Although many of these functional foods and nutraceuticals have been found to have high therapeutic potential, future studies should include a well-designed clinical trial assessing different combinations of these nutrients to realize possible additive and/or synergistic effects on health outcomes. Many functional foods have antioxidant and anti-inflammatory activities, by mechanisms that may require further investigation. Therefore, these functional foods should be incorporated into a healthy diet to provide cardio-protective benefits and hence lower atherosclerotic vascular diseases risk.

\section{REFERENCES}

[1] Aguirre, R. and May, J.M. (2008). Inflammation in the vascular bed: importance of vitamin C. Pharmacology and Therapeutics, vol. 119, no. 1, pp. 96-103.

[2] Alenghat, F.J. and Davis, A.M. (2019). Management of Blood Cholesterol. JAMA 321:800-801 Visioli, F. and Poli, A. (2019). Dietary advice to cardiovascular patients. A brief update for physicians. Monaldi Arch Chest Dis 89

[3] Anderson, J. W., Johnstone, B. M. and Cook-Newell, M. E. (1995). Meta-analysis of the effects of soy protein intake on serum lipids. New England Journal of Medicine, vol. 333, no. 5, pp. 276-282.

[4] Appel, L.J., Miller, E.R. and Jee, S.H. (2000). Effect of dietary patterns on serum homocysteine: results of a randomized, controlled feeding study. Circulation, vol. 102, no. 8, pp. 852-857.

[5] Bjelakovic, G. and Gluud, C. (2007). Surviving antioxidant supplements, Journal of the National Cancer Institute, vol. 99, no. 10, pp. 742-743.

[6] Broekmans, W.M., Kl"opping-Ketelaars, I. A. and Schuurman, C. R. (2000). Fruits and vegetables increase plasma carotenoids and vitamins and decrease homocysteine in humans. Journal of Nutrition, vol. 130, no. 6, pp. 1578- 1583.

[7] Chopra, M., O'Neill, M., Keogh, N., Wortley, G., Southon, S. and Thurnham, D. (2000). Influence of increased fruit and vegetable intake on plasma and lipoprotein carotenoids and LDL oxidation in smokers and nonsmokers. Clinical Chemistry, vol. 46, no. 11, pp. 1818-1829.

[8] Chopra, M., O'Neill, M.E., Keogh, N., Wortley, G., Southon, S. and Thurnham, D.I. (2000). Influence of increased fruit and vegetable intake on plasma and lipoprotein carotenoids and LDL oxidation in smokers and nonsmokers. Clinical Chemistry, vol. 46, no. 11, pp. 1818-1829.

[9] Csonka, C., Sárközy, M., Pipicz, M., Dux, L. and Csont, T. (2016). Modulation of Hypercholesterolemia-Induced Oxidative/Nitrative Stress in the Heart. Oxidative Med Cell Longev.2016:3863726. 
[10] Davidson, M.H., Maki, K.C. and Dicklin, M.R. (2009). Effects of consumption of pomegranate juice on carotid intima-media thickness in men and women at moderate risk for coronary heart disease. American Journal of Cardiology, vol. 104, no. 7, pp. 936-942.

[11] De Felice, S. L. (1995). The nutraceutical revolution: its impact on food industry R\&D. Trends in Food Science and Technology. vol. 6, no. 2, pp. 59-61.

[12] Engelhard, Y.N., Gazer, B. and Paran, E. (2006). Natural antioxidants from tomato extract reduce blood pressure in patients with grade-1 hypertension: a double-blind, placebo controlled pilot study. American Heart Journal, vol. 151, no. 1, pp. 100.e1-100.e6

[13] Erkkil”a, A.T. and Lichtenstein, A.H. (2006). Fiber and cardiovascular disease risk: how strong is the evidence? Journal of Cardiovascular Nursing, vol. 21, no. 1, pp. 3-8.

[14] Ferrari, C.K. (2004). Functional foods, herbs and nutraceuticals: towards biochemical mechanisms of healthy aging. Biogerontology, vol. 5, no. 5, pp. 275-289.

[15] Galimanis, A., Mono, M.L., Arnold, M., Nedeltchev, K. and Mattle, H.P (2009). Lifestyle and stroke risk: A review. Curr Opin Neurol. 22:60-68.

[16] Grassi, D., Lippi, C., Necozione, S., Desideri, G. and Ferri, C. (2005). Short-term administration of dark chocolate is followed by a significant increase in insulin sensitivity and a decrease in blood pressure in healthy persons. American Journal of Clinical Nutrition, vol. 81, no. 3, pp. 611-614.

[17] Hooper, L., Kroon, P.A. and Rimm, E.B. (2008). Flavonoids, flavonoid-rich foods, and cardiovascular risk: a meta-analysis of randomized controlled trials. American Journal of Clinical Nutrition, vol. 88, no. 1, pp. 38-50.

[18] Krinsky, N.I. and Johnson, E.J. (2005). Carotenoid actions and their relation to health and disease. Molecular Aspects of Medicine, vol. 26, no. 6, pp. 459-516.

[19] Kushi, L.H., Folsom, A.R., Prineas, R.J., Mink, P.J., Wu, Y. and Bostick, R.M. (1996).

[20] Dietary antioxidant vitamins and death from coronary heart disease in postmenopausal women.

[21] New England Journal of Medicine, vol. 334, no. 18, pp. 1156- 1162, 1996.

[22] Laudadio, V., Ceci, E., Lastella, N.M. and Tufarelli, V. (2015). Dietary high-polyphenols extravirgin olive oil is effective in reducing cholesterol content in eggs. Lipids Health Dis. 14(1):5.

[23] Lee, Y.S. and Wander, R.C. (2005). Reduced effect on apoptosis of 4-hydroxyhexenal and oxidized LDL enriched with n-3 fatty acids from postmenopausal women. Journal of Nutritional Biochemistry, vol. 16, no. 4, pp. 213-221.

[24] Libby, P. (2003). Vascular biology of atherosclerosis: Overview and state of the art. Am J Cardiol 91(Suppl):3A-6A.

[25] Liu, S., Buring, J.E., Sesso, H.D., Rimm, E.B., Willett, W.C. and Manson, J.E. (2002). A prospective study of dietary fiber intake and risk of cardiovascular disease among women. Journal of the American College of Cardiology, vol. 39, no. 1, pp. 49-56, 2002.

[26] Lutsey, P.L., Jacobs, D.R. and Kori, S. (2007). Whole grain intake and its cross-sectional association with obesity, insulin resistance, inflammation, diabetes and subclinical CVD: the MESA Study. British Journal of Nutrition, vol. 98, no. 2, pp. 397-405.

[27] Madonna, R. and De Caterina, R. (2009). Prolonged exposure to high insulin impairs the endothelial PI3-kinase/Akt/nitric oxide signalling. Thromb Haemost. 101:345-350.

[28] Massaro, M., Scoditti, E., Carluccio, M.A. and Caterina, R. (2010). Nutraceuticals and Prevention of Atherosclerosis: Focus on $\omega$-3Polyunsaturated Fatty Acids and Mediterranean Diet Polyphenols. Cardiovascular Therapeutics 28 : e13-e19

[29] Mozaffarian, D. (2008). Fish and n-3 fatty acids for the prevention of fatal coronary heart disease and sudden cardiac death. American Journal of Clinical Nutrition, vol. 87, no. 6, pp. 1991S-1996S.

[30] Perez-Jimenez, J. and Saura-Calixto, F. (2008). Grape products and cardiovascular disease risk factors. Nutrition Research Reviews, vol. 21, no. 2, pp. 158-173.

[31] Ros, E., N'ũnez, I. and P'erez-Heras, A. (2004). A walnut diet improves endothelial function in hypercholesterolemic subjects: a randomized crossover trial. Circulation, vol. 109, no. 13, pp. 1609-1614.

[32] Ross, R. (1999). Atherosclerosis-An inflammatory disease. N Engl J Med. 340:115-126.

[33] Sabat'e, J. and Ang, Y. (2009). Nuts and health outcomes: new epidemiologic evidence. American Journal of Clinical Nutrition, vol. 89, no. 5, pp. 1643S-1648S.

[34] Samman, S., Sivarajah, G., Man, J.C., Ahmad, Z.I., Petocz, P. and Caterson, I.D. (2003). A mixed fruit and vegetable concentrate increases plasma antioxidant vitamins and folate and lowers plasma homocysteine in men. Journal of Nutrition, vol. 133, no. 7, pp. 2188-2193 
[35] Sesso, H.D., Buring, J.E. and Christen, W.G. (2008). Vitamins E and C in the prevention of cardiovascular disease in men: the physicians' health study II randomized controlled trial. JAMA - Journal of the AmericanMedical Association, vol. 300, no. 18, pp. 2123-2133.

[36] Singh, U., Devaraj, S. and Jialal, I. (2005). Vitamin E, oxidative stress, and inflammation. Annual Review of Nutrition, vol. 25, pp.151-174.

[37] Tufarelli, V., Laudadio, V. and Casalino, E. (2016). An extra-virgin olive oil rich in polyphenolic compounds has antioxidant effects in meat-type broiler chickens. Environ Sci Pollut Res. 23(7):6197-204.

[38] Ueeda, M., Doumei, T. and Takaya, Y. (2008). Serum N-3 polyunsaturated fatty acid levels correlate with the extent of coronary plaques and calcifications in patients with acute myocardial infarction. Circulation Journal, vol. 72, no. 11, pp. 1836-1843.

[39] Visioli, F., Poli, A., Richard, D. and Paoletti, R. (2008). Modulation of inflammation by nutritional interventions. Curr Atheroscler Rep 10:451-453

Citation: A.M. Adewolu, F.G. Olorunfemi, "Management of Atherosclerosis: Prospect of Functional Foods and Nutraceuticals", International Journal of Research Studies in Biosciences, 8(5), pp. 1-6. DOI:https://doi.org/10.20431/2349-0365.0805001

Copyright: (C) 2020 Authors, This is an open-access article distributed under the terms of the Creative Commons Attribution License, which permits unrestricted use, distribution, and reproduction in any medium, provided the original author and source are credited. 